ScIDice

\section{Cell Supplying to the Experimentally Induced Absorbable Suture Thread Foreign Body Granuloma from the Bone Marrow Tissues}

Research Article

\begin{abstract}
Nakayasu $\mathrm{Y}^{1}$, Aoki $\mathrm{S}^{2}$, Shoumura $\mathrm{M}^{2,3}$, Osuga $\mathrm{N}^{2,3}$, Okafuji $\mathrm{N}^{1}$, Nakano $\mathrm{K}^{4}$, Nagatsuka $\mathrm{H}^{4}$, Tsujigiwa $\mathrm{H}^{5}$, Kawakami $\mathrm{T}^{*}$
${ }^{1}$ Department of Hard Tissue Research, Matsumoto Dental University Graduate School of Oral Medicine, Shiojiri, Japan.

${ }^{2}$ Department of Pedatric Dentistry, Matsumoto Dental University School of Dentistry, Shiojiri, Japan.

${ }^{3}$ Department of Oral Health Promotion, Matsumoto Dental University Graduate School of Oral Medicine, Shiojiri, Japan.

${ }^{4}$ Department of Oral Pathlogy and Medicine, Okayama University Graduate School of Medicine, Dentistry and Pharmaceutical Sciences, Okayama, Japan.

${ }^{5}$ Laboratory of Histopathology, Department of Life Science, Okayama University of Science, Okayama, Japan.
\end{abstract}

\title{
Abstract
}

Using the experimental system of GFP (Green florescence Protein) bone marrow transplanted rats, we implanted the Vicryl absorbable suture thread in subcutaneous tissue and examined the formation of foreign body granuloma histopathologically. We also compared the main cellular components, namely, the macrophage and foreign body giant cell immunohistochemically using GFP to confirm their origin. Histologically, the disintegrated suture thread was observed as a circular in void surrounded by the proliferation of macrophages and foreign body giant cells. Fibrous connective tissue including the fibroblasts was interposed among large masses. Even after 6 months, some clusters considered to be residues of macrophages that grew on the suture were still remained. Immunohistochemical examination of GFP showed that all proliferated macrophages and foreign body giant cells were GFP-positive. However, the relatively thin fibrous tissues formed on the outermost layer of the granulation tissue growth were mostly GFP-negative. Based on the results of the experiment, the macrophages and foreign body giant cells that are GFP-positive were derived from the mesenchymal tissue of transplanted bone marrow tissues.

Keywords: Foreign Body Granuloma; Macrophage; Foreign Body Giant Cells; Absorbable Suture; Bone Marrow Tissue; GFP; Bone Marrow Transplanted Rats.

Abbreviations: GFP: Green Florescence Protein; M $\varphi$ : Macrophage; FBGC: Foreign Body Giant Cells.

\section{Introduction}

Sutures thread are commonly used in various parts of the body in the medical field. Absorbable sutures are also used in the oral cavity during surgical procedures. Many of these absorbable sutures are made of chemical compounds and one example includes suture made of glycolic acid/lactic acid polyester (polyglactin) [13]. Foreign body reaction is expected to naturally occur during the dissolution process due to the breakdown and absorption of the suture. However, the details of the process have not been disclosed. We examined the histopathological response of rat subcutaneous tissue after Vicryl absorbable suture was implanted until
6 months and reported the results [4]. It was confirmed that macrophages $(\mathrm{M} \varphi)$ including many foreign body giant cells (FBGC) appear on the suture embedded in subcutaneous tissue. In this study, we used GFP bone marrow transplanted rat to investigate whether the $\mathrm{M} \varphi$ including FBGC emerging around the absorbable suture is derived from bone marrow tissue.

\section{Materials and Methods}

GFP bone marrow transplanted rats were used as experimental animals. Five-week old female SD rats (Charles River Laboratories Japan, Inc., Yokohama, Japan) and 6-week old female GFP

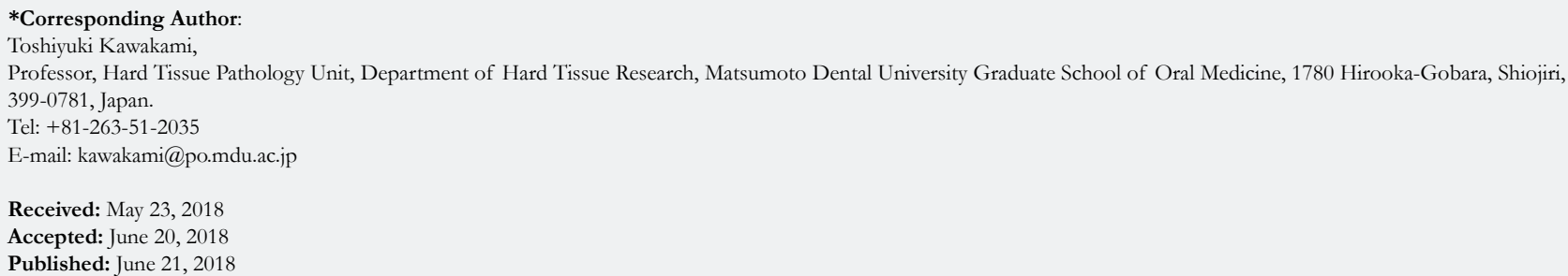

Copyright: Kawakami $\mathbf{T}^{\circ}$ 2018. This is an open-access article distributed under the terms of the Creative Commons Attribution License, which permits unrestricted use, distribution and reproduction in any medium, provided the original author and source are credited. 
transgenic rat SD-Tg (CAG-EGFP) (Shimizu Laboratories Supplies Co., Kyoto, Japan) were used to prepare the GFP bone marrow transplanted rats. GFP transgenic rat was sacrificed under ether anesthesia and the femur and tibia were excised. The soft tissues were removed as much as possible before the bone marrow cells were collected. Bone marrow cells were washed with RPMI 1640 medium containing antibiotics and then replaced with HBBS. Five-week old female rats syngeneic to GFP rats were irradiated with 10 Gray of X-rays and transplanted with $1 \times 10^{7}$ bone marrow cells or more from the tail vein. Grafted rats with transplanted bone marrow at 4 weeks after bone marrow transplantation were used.

Using these rats, a glycolic acid/lactic acid polyester suture called Vicryl (V) (Johnson and Johnson Japan Co., Tokyo, Japan) was bundled and implanted in the dorsal subcutaneous tissue. Briefly, under general anesthesia by intraperitoneal injection of pentobarbital, the back of the rats was shaved, incised and the suture was implanted in the subcutaneous tissue. Then after, the incision was sutured 2 times. After 2 weeks, 1 month, 3 months and 6 months, the implanted site-tissues were removed as one block, fixed in $10 \%$ neutral buffered formalin and paraffin-embedded sections were made and examined histopathologically.

For immunohistochemistry, the specimens were pretreated using citrate buffer (citrate buffer pH 6.0, LSI Medience Co., Tokyo, Japan) in an autoclave at $121^{\circ} \mathrm{C}$ for $10 \mathrm{~min}$. This was followed by blocking with Protein Block Serum-free (Dako Japan Co., Tokyo, Japan) for $30 \mathrm{~min}$ at room temperature. Anti-GFP antibody (ab290: Abcam, Cambridge, UK; 1/2000) was used as the primary antibody and the reaction was carried out at $4^{\circ} \mathrm{C}$ overnight. After secondary reaction with anti-rabbit immunoglobulin antibody for $30 \mathrm{~min}$, the slides were washed with PBS and then developed with DAB. Hematoxylin was used for nuclear staining.

This study was planned according to the Matsumoto Dental University Animal Experiment Committee and Okayama University Animal Experiment Guidelines and was conducted under the review and approval of both animal experimental committees.

\section{Results}

\section{Histopathological Examination}

At 2 weeks after implantation, the suture was observed as voids in various sizes according to its direction. $\mathrm{M} \varphi$ and multinucleated FBGC proliferated around the voids. A relatively thin fibrous tissue was formed on the outermost layer of the granulation tissue (Figure 1a). Fibrous connective tissue including fibroblasts was interposed between clusters of FBGC around the suture. At 1 month after implantation, the void left by the suture decreased in size. $\mathrm{M} \varphi$ filled the space for the most part. Furthermore, the FBGC were larger compared to those at 2 weeks and the number of nuclei also increased (Figure 1b). At 3 months after implantation, $\mathrm{M} \varphi$ almost disappeared forming clusters of residues (Figure 1c). Even at 6 months after implantation, clusters of residual cells that grew on the suture were still observed (Figure 1d). However, they were fairly small and the number of nuclei decreased compared to those seen at 3 months.

\section{Immunohistochemical Examination}

At 2 weeks after implantation, the $\mathrm{M} \varphi$ and FBGC were all GFPpositive. Both cell membrane and cytoplasm of $\mathrm{M} \varphi$ were heavily stained with GFP. The nucleus was stained with hematoxylin and is pushed to one side. The cytoplasm contains substances engulfed by the cell and was stained with hematoxylin. Similarly, the cell membrane of FBGC was stained with GFP and the cytoplasm was slightly stained with hematoxylin. The outer layer of fibrous tissue of the expanded granulation tissue was GFPnegative (Figure 2a).

One month after implantation, the voids became smaller. The fibrous tissue was filled with $\mathrm{M} \varphi$ and fibroblasts which were GFPpositive. The stain of the cell membrane and cytoplasm in $\mathrm{M} \varphi$ was more intense compared to 2 weeks. However, the intracellular substances resulting from phagocytosis lightly reacted to GFP compared to 2 weeks. The multinucleated giant cells were stained similarly to those at 2 weeks (Figure $2 \mathrm{~b}$ ).

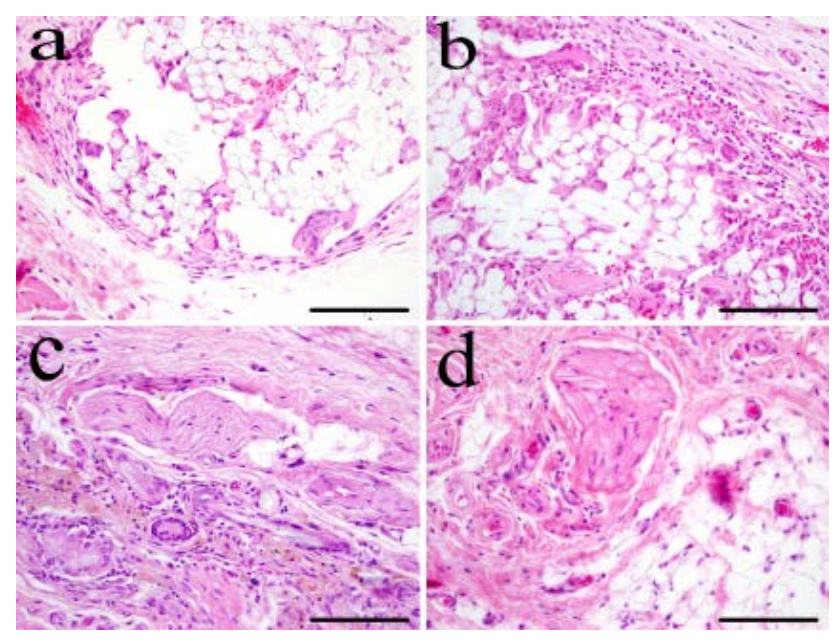

Figure 1. Histopathological image of cell proliferation at the site where the suture was embedded (HE stain). Although the proliferation of $\mathrm{M} \varphi$ and FBGC are observed from 2 weeks to 1 month, almost of $\mathrm{M} \varphi$ deleted and some are remained after 3 months. The nuclei count in some clusters of $M \varphi$ decrease at 6 months (a: 2 weeks; b: 1 month; c: 3 months; d: 6 months; Scale bars $=100 \mathrm{~m})$. 


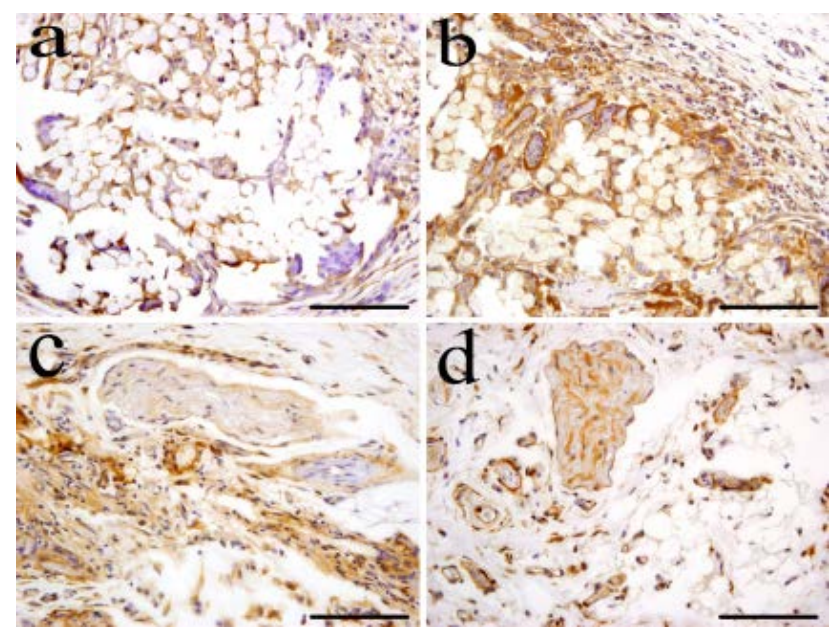

Figure 2. Immunohistopathological image cell proliferation at the implanted site (GFP-IHC). From 2 weeks to 1 month, the cell membrane of bone marrow-derived $\mathrm{M} \varphi$ and FBGC are deeply stained with GFP and the cytoplasm was lightly stained with GFP. However, the fibroblasts were stained only with hematoxylin; the cytoplasm is lightly stained and the nucleus was intensely stained with hematoxylin. GFP-positive $M \varphi$ deceased in the tissues at 3-month-specimen.In 6-month-specimens, the clusters of residual some $M \varphi$ are GFP-positive. (a: 2 weeks; b: 1 month; c: 3 months; $d: 6$ month; Scale bars=100m).

Three months after implantation, residual $\mathrm{M} \varphi$ that formed clusters were still observed. The cell membrane was densely positive to GFP and the cytoplasm was lightly stained with hematoxylin. The cell membrane of the multinucleated giant cells was stained with GFP and the cytoplasm was stained with hematoxylin. Some of the fibroblasts in the fibrous tissues surrounding the clusters of residual $\mathrm{M} \varphi$ and and the around tissues were sometimes possitive to GFP (Figure 2c).

Six months after implantation, clusters of residual $\mathrm{M} \varphi$ that proliferate around the suture were GFP-positive. The cell membrane was stained with GFP and the cytoplasm was stained with hematoxylin (Figure 2d).

\section{Discussion}

Sutures are widely utilized in the medical field. Some absorbable sutures are also used in the oral cavity during surgical procedures. Although it can be assumed that a foreign body reaction occurs during the process of disintegration or absorption of the suture, details on the mechanism have not been disclosed.

Therefore, we conducted an experiment on the histopathological examination of absorbable sutures and reported the results [4]. Histopathologically, the suture was observed as a void surrounded by $\mathrm{M} \varphi$ and multinucleated FBGC. Fibrous connective tissue with fibroblasts was observed interposed among the clusters of FBGC. Six months after implantation, some clusters of residual cells that proliferated around the suture could still be observed.

Mononuclear cells and FBGC were also reported to be positive to CD68 in immunohistochemical study. Furthermore, it was clearly shown that FBGC was formed by the coalescence of $\mathrm{M} \varphi$ [4]. Similar histopathological findings were obtained in this study using the same experimental system.

A rat model of bone marrow transplantation was used due to our assumption that the cells that proliferated around the embedded suture were supplied by the bone marrow [5-7]. In GFP transgenic rats, all the cells constituting the tissue expressed the
GFP protein and even if the transplanted bone marrow-derived cells differentiate into other cells, tracking of the differentiated cells was possible because of the GFP protein they carry. So far, Tsujigiwa et al., studied the pluripotency of bone marrow-derived cells by using this technique and learned that the cells migrated and differentiated into constituent cells of the tooth and the periodontal tissues [8]. They showed that GFP-positive cells derived from transplanted bone marrow have migrated to the oral cavity within a short period of time, specifically, one month after transplantation and were distributed in the teeth and surrounding tissues. According to the research group, some of the cells that were positive to GFP include dendritic cell-like cells, Langerhans cells, osteoclasts, periodontal fibroblasts and some vascular endothelial cells in the periodontium of the mouse [9-13]. Furthermore, our research group have overviewed the role of bone marrow derived cells in the repair of the periodontal ligament inflammatory lesions [14]. The review manuscript concluded that the bone marrow derived mesenchymal cells migrate and differentiate into the tissue specific cells.

Based on the results of the immunohistochemical examination, nearly all cells of the granulation tissue which proliferated at the site where the suture was implanted were GFP-positive. Furthermore, within the granulation tissue, small amounts of fibroblasts and collagen fibers were interspersed and they were GFP-negative.

In the past, our research group also conducted experiments using cholesterin embedded in mouse models as representatives of foreign body granulomas. Cholesterin was implanted into the subcutaneous tissue of the dorsal region of the mouse and histological responses, as well as some immunohistochemical analysis, were reported [15]. The results observed on the granulation tissue using GFP in this experiment were roughly similar to the findings of Sakai et al., using cholesterin crystals implanted in the subcutaneous tissues in GFP-transplanted model mice [15].

The staining pattern of the cytoplasm in proliferated $\mathrm{M} \varphi$ was similar to the peripheral stain of round structures in the center of the cells. Some of them stained pale violet and some were 
almost devoid of stain. These structures are vacuoles resulting from phagocytosis by $\mathrm{M} \varphi$ and the change in stain was considered to be due to the degree of hydrolysis of the absorbable suture as time passed by.

In this experiment, we showed that both $\mathrm{M} \varphi$ and FBGC were positive to GFP while the fibrous tissues including the fibroblasts interspersed between $\mathrm{M} \varphi$ and FBGC were negative to GFP. The results showed that the $\mathrm{M} \varphi$ and FBGC were derived from the transplanted bone marrow mesenchymal cells.

\section{Acknowledgement}

This research was supported by Japan Society for the Promotion of Scientific Research, Basic Research C (\#26463031 and 17K11862).

\section{References}

[1]. Aston SJ, Rees TD. Vicryl Sutures. Aesth Plast Surg. 1977;1:259-293.

[2]. Bird IN, Silver IA, Gorham SD, French DA. In vivo degradation of collagenvicryl materials in rabbit ear chambers. J Mater Sci Mater Med. 1991 Jan 1;2(1):36-42.

[3]. Munton CG, Phillips CI, Martin B, Bartholomew RS, Capperauld I. Vicryl (Polyglactin 910): a new synthetic absorbable suture in ophthalmic surgery. A preliminary study. Br J Ophthalmol. 1974 Nov;58(11):941-7. PubMed PMID: 4281663.

[4]. Nakayasu Y, Matsuda S, Nishikawa J, et al. Subcutaneous tissue reactions to Bioabsorbable suture Thread in rats. J Jpn Ass Dent Traumatol. 2017 Dec 31:13:23-28.

[5]. Asahara T, Masuda H, Takahashi T, Kalka C, Pastore C, et al. Bone marrow origin of endothelial progenitor cells responsible for postnatal vasculogenesis in physiological and pathological neovascularization. Circ Res. 1999 Aug 6;85(3):221-8. PubMed PMID: 10436164

[6]. Crosby JR, Kaminski WE, Schatteman G, Martin PJ, Raines EW, et al. Endothelial cells of hematopoietic origin make a significant contribution to adult blood vessel formation. Circ Res. 2000 Oct 27;87(9):728-30. PubMed PMID: 11055974.

[7]. Zampetaki A, Kirton JP, Xu Q. Vascular repair by endothelial progenitor cells. Cardiovasc Res. 2008 Jun 1;78(3):413-21. PubMed PMID: 18349136.

[8]. Tsujigiwa H, Katase N, Sathi GA, Buery RR, Hirata Y, et al. Transplanted Bone Marrow derived Cells Differentiated to Tooth, Bone and Connective Tissues in Mice. J Hard Tissue Biol. 2011;20(2):147-52.

[9]. Tomida M, Tsujigiwa H, Nakano K, Muraoka R, Nakamura T, et al. Promotion of transplanted bone marrow-derived cell migration into the periodontal tissues due to orthodontic mechanical stress. Int J Med Sci. 2013 Aug 9;10(10):1321-6. doi: 10.7150/ijms.6631. PubMed PMID: 23983592.

[10]. Muraoka R, Tsujigiwa H, Nakano K, Katase N, Tamamura R, et al. Transplanted bone marrow-derived cell migration into periodontal tissues and cell differentiation. J Hard Tissue Biol. 2011;20(4):301-6.

[11]. Takaya T, Mimura H, Matsuda S, Nakano K, Tsujigiwa H, et al. Cytological kinetics of periodontal Ligament in an experimental occlusal trauma model. Int J Med Sci. 2015 Jun 23;12(7):544-51. doi: 10.7150/ijms.12217. PubMed PMID: 26180510.

[12]. Kaneko K, Matsuda S, Muraoka R, Nakano K, Iwasaki T, et al. Histological evaluation of periodontal ligament in response to orthodontic mechanical stress in mice. Int J Med Sci. 2015 Aug 10;12(9):689-94. doi: 10.7150/ ijms.12883. PubMed PMID: 26392805.

[13]. Matsuda S, Shoumura M, Osuga N, Tsujigiwa H, Nakano K, et al. Migration and differentiation of GFP-transplanted bone marrow-derived cells into experimentally induced periodontal polyp in mice. Int J Med Sci. 2016 Jun 29;13(7):500-6. doi: 10.7150/ijms.15671. PubMed PMID: 27429586.

[14]. Matsuda S, Nakano K, Tsujigiwa H, Takabatake K, Kawakami T. Overview of Cytological Dynamics of Periodontal Ligament Inflammatory Lesions. Int J Dentistry Oral Sci. S. 2016 Sep 8;9:1-7.

[15]. Sakai K, Nakano K, Matsuda S, Tsujigiwa H, Ochiai T, et al. Pathological analysis of cell differentiation in cholesterol granulomas experimentally induced in mice. Int J Med Sci. 2016 Feb 19;13(3):220-4. doi: 10.7150/ ijms.13853. PubMed PMID: 26941582. 